Document downloaded from:

http://hdl.handle.net/10251/82103

This paper must be cited as:

Payri, R.; Gimeno, J.; De La Morena, J.; Battiston, PA.; Wadhwa, A.; Straub, R. (2016). Study of new prototype pintle injectors for diesel engine application. Energy Conversion and Management. 122:419-427. doi:10.1016/j.enconman.2016.06.003.

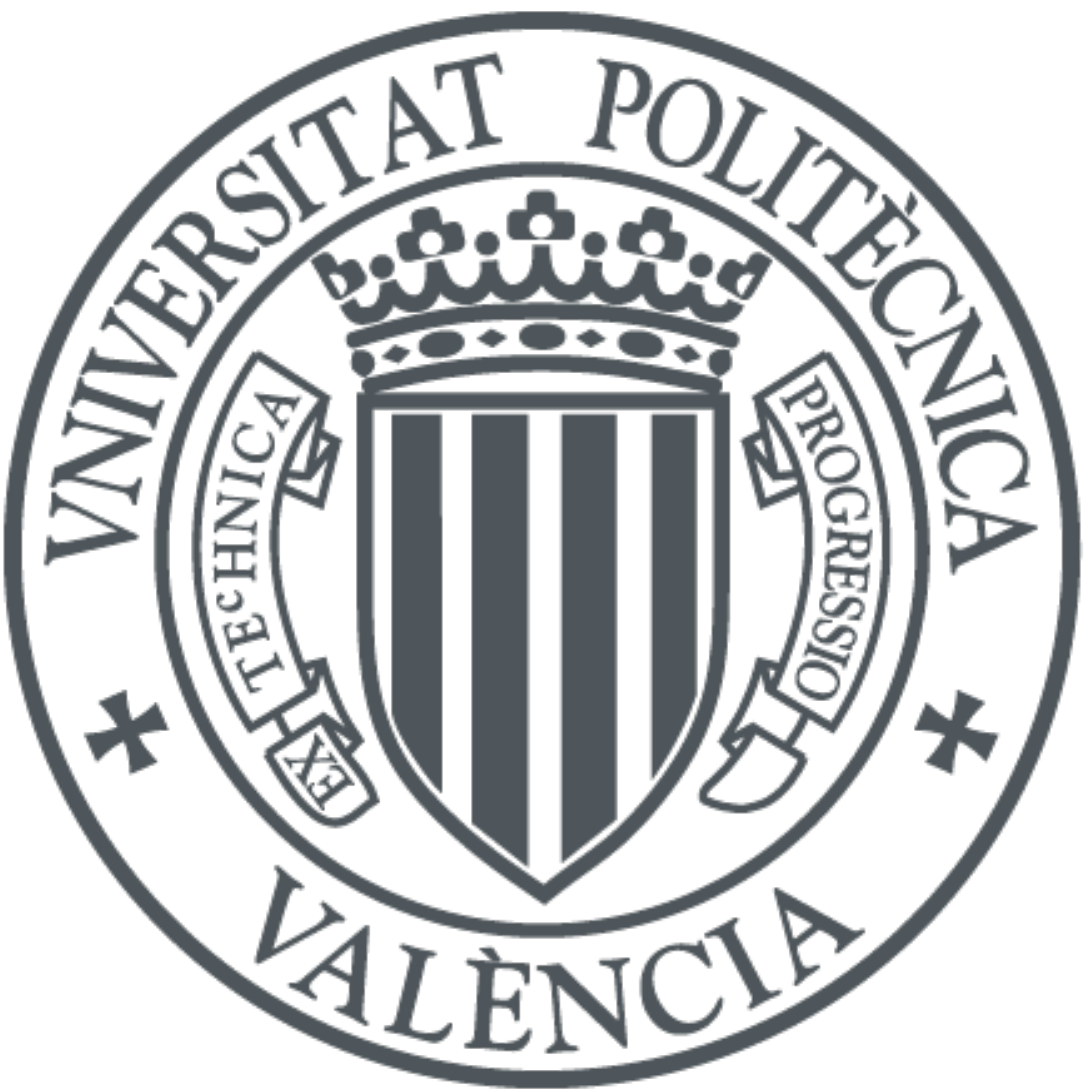

The final publication is available at

http://doi.org/ 10.1016/j.enconman.2016.06.003

Copyright Elsevier

Additional Information 


\title{
Study of new prototype pintle injectors for diesel engine application.
}

\author{
Raul Payri ${ }^{\mathrm{a}}$, Jaime Gimeno ${ }^{\mathrm{a}}$, Joaquin De la Morena ${ }^{\mathrm{a}, *}$, Paul A. Battiston ${ }^{\mathrm{b}}$, Amrita \\ Wadhwa $^{\mathrm{b}}$, Robert Straub ${ }^{\mathrm{b}}$ \\ ${ }^{a}$ CMT Motores Termicos, Universitat Politècnica de València \\ Camino de Vera s/n 46022 Valencia (Spain) \\ ${ }^{b}$ General Motors Powertrain, Global Advanced and Racing Engine Engineering \\ 800 North Glenwood Ave, Pontiac, MI 48340 (United States)
}

\begin{abstract}
A new prototype common rail injector featuring a complete new nozzle design concept was exhaustively characterized both from the hydraulic and spray formation point of view. A commercial injection rate meter together with a spray momentum test rig were used to determine the flow characteristics at the nozzle exit. A novel high pressure and high temperature chamber (up to $15 \mathrm{MPa}$ and $1000 \mathrm{~K}$ ) was used to determine liquid length and vapor penetration. Using these tools, three different pintle nozzle designs, with specific features in the outlet section, were studied. The test matrix included a sweep of injection pressure up to 2000 bar and a sweep of ambient temperature up to $950 \mathrm{~K}$. The results obtained show that pintle nozzles offer great potential in terms of fuel mass flux controlled by variable nozzle geometry. Effects in the hydraulic measurements and spray images due to the variable geometry were observed and characterized.
\end{abstract}

Keywords: pintle nozzle, diesel, injection, spray

\section{Introduction}

On diesel engines, the combustion process is significantly driven by the performance of the fuel injection system. For this reason, the characteristics of fuel injectors and their impact on spray formation and engine performance have been widely studied in the literature. Sun et al. 11 showed that the geometrical details of the fuel injector nozzle holes affect its internal flow characteristics, including the formation of cavitation. Jiang et al. 2] analyzed that the flow conditions inside the nozzle also significantly linked to the physical properties of the fuel, especially to the viscosity. Salvador et al. 3 found through CFD simulations that while the flow characteristics are a direct function of the nozzle hole geometry when the injector arrives to stabilized conditions, during the first stages of the injection the flow is strongly affected by the position of the needle itself.

\footnotetext{
${ }^{*}$ Corresponding author

Email address: joadela@mot.upv.es (Joaquin De la Morena)
} 
Energy Conversion and Management 122 (2016) 419-427,

Similar result was obtained experimentally by Viera et al. 4] using a direct-acting piezoelectric injector, which showed that the injection velocity was affected by the needle lift up to approximately $50-70 \mu m$, depending on the injection pressure level. Dumouchel [5] reviewed the different factors affecting the spray atomization process, showing that it is improved by increases in the nozzle outlet velocity and by the appearance of cavitation inside it. Payri et al. [6] used a high magnification visualization technique to study the spray formation in the near-nozzle field, concluding that the nozzle effective outlet area and velocity enhance the spray opening angle and the primary atomization characteristics. Salvador et al. 7] used a 1D spray model, based on the analogy of the liquid spray to a gas jet, to show that the local distribution of equivalence ratio is directly linked to the spray velocity and the non-dimensional Schmidt number, which depends on the fuel and discharge ambient physical properties. As a consequence, combustion efficiency and soot emissions are also impacted by the injection characteristics [8]

On realistic engine conditions, the spray outlet velocity (and, consequently, the spray formation characteristics) has a transient evolution depending on the needle dynamics [9. As stated before, high injection velocities are preferred to optimize fuel atomization and mixing processes. For this reason, injection system suppliers have made efforts to produce injectors with faster dynamic behavior and capable of working at higher injection pressures, which approach square-like injection rate profiles. Johnson et al. [10] studied the injection rate and spray characteristics of a diesel injector in the range of 2000-3000 bar. Wloka et al. 11 combined internal nozzle flow simulations with single-cylinder engine testing, showing that these injection pressure levels combined with a proper nozzle geometry design can lead to soot emissions reduction. Mohan et al. [12] confirmed through multi-cylinder engine testing that the use of ultra-high injection pressures could help to reduce soot emissions, and also engine efficiency and $\mathrm{CO} / \mathrm{HC}$ emissions. However, such high injection velocities tend to produce steep initial heat release rates, inducing high $N O_{x}$ emissions and cylinder pressure gradients (linked to higher combustion noise) [13]. To mitigate this effect, more and more complex multiple injection strategies have been developed over the years [14. In this sense, Dhar et al. 15] studied the effect of a pilot injection, coupled with different fuel formulations, to module the shape of the heat release rate and improve the soot- $N O_{x}$ trade-off. Xu et al. [16 observed that an early pre-injection could help to increase thermal efficiency and reduce $N O_{x}$ emissions simultaneously on a natural gas fueled engine. Mahr 13 proposed the addition of a late post injection to improve the soot oxidation process. Nevertheless, the use of multiple injection strategies come with the cost of an increased calibration complexity.

Another alternative to produce a similar result would be a direct modulation of the injection rate shape [17. Mohan et al. [18] studied a boot injection shape through numerical simulations, resulting in reduced emissions compared to a square injection rate shape. He et al. [19] performed simulations on a wider variation of injection rate profiles, being the optimal a so-called "hump" shape, characterized by increased injection rate and velocities in the initial and final stages of the injection event, while reduced values are used in the middle. Benajes et al. 20] assessed experimentally the impact of injection rate shaping by implementing a device to modulate the injection pressure along the engine cycle. Other methods are based on a direct control on the needle position along the injection event [21]. A low needle lift produces a throttling effect on the needle seat, inducing a pressure drop, which results in a reduced injection rate compared 
Energy Conversion and Management 122 (2016) 419-427,

to maximum needle lift conditions. Both strategies have shown potential to modulate injection rate, but with the drawback of impaired injection velocity (and consequently spray atomization). Postrioti et al. 22] evaluated the possibility of shaping a main injection event by positioning a close-pilot injection by leveraging the combined effect of the different instantaneous pressure achieve in the sac and control volume and the residual electromagnetic current existing in the solenoid coil from the first injection event. Combustion performance of a similar injection strategy was evaluated by d'Ambrosio and Ferrari 23], with promising results in terms of reduced soot emissions. Nevertheless, such behavior is difficult to be controlled on real engine conditions.

This paper explores a variable-area injector as a way to modulate the injection rate shape minimizing the effect on injection velocity. The variable-area concept is achieved using a pintle nozzle design. Although pintle nozzle designs are not standard in automotive diesel production engines, these designs could be of relevance for alternative architectures such as opposed-piston engines. These architectures typically require combustion systems with side-injection layouts of one or more injectors with narrow plume angle nozzles. For example, Venugopal et al. 24] explored side-injector orientation and control using conventional multi-holed nozzles on a diesel 2-stroke opposed piston to study the impacts on combustion and piston thermal loading. The main difference between the pintle nozzles used in this study and other pintle nozzles studied in the literature [25] is the relative shape of the nozzle and the needle. The pintle nozzles studied in this paper are designed so that the area available for the fluid to pass evolves in a certain way, producing a characteristic injection rate profile. Three different designs are analyzed in the paper by comparing hydraulic behavior and spray characteristics.

The paper is divided in 5 sections. In section 2 , the pintle nozzle concept used for the study is proposed, together with the three different geometries used on it. Section 3 gives some details of the different experimental tools and methodologies employed to analyze the hydraulic performance and spray behavior characteristics. Section 4 summarizes the main findings obtained in terms of their hydraulic behavior and spray characteristics. Finally, the main conclusions of the study are described in section 5 .

\section{Description of pintle nozzles}

In this section, the pintle nozzle concept proposed along the paper is briefly described and compared to standard diesel nozzle. Additionally, the three pintle nozzle variations used along the study are detailed.

\subsection{Concept}

A schematic of a standard diesel injection nozzle is seen in Figure1 1. In these nozzles, three main components can be defined: the needle, the sac and the hole (or holes), which can vary in number and orientation depending on the particular nozzle design. In the case of the figure, a single-hole axi-symmetric hole geometry, as it could be used for sideinjection combustion systems, is represented [24. When the injector is closed, the needle separates the high-pressure region of the nozzle (corresponding to the internal channel where the needle is located) from the low-pressure region, which includes the sac and the discharge hole. When the injector opens and the needle moves up, the mass flow through the nozzle hole depends on the area of this hole, which is constant, and the pressure in 


\section{a) Standard nozzle}

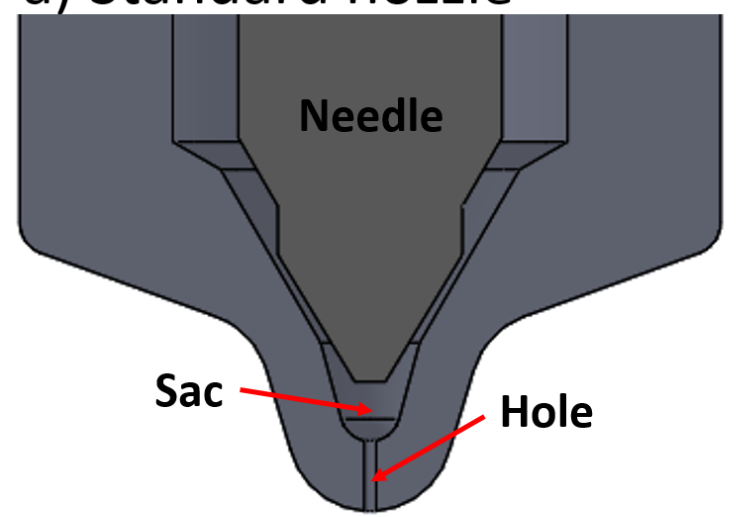

b) Pintle nozzle

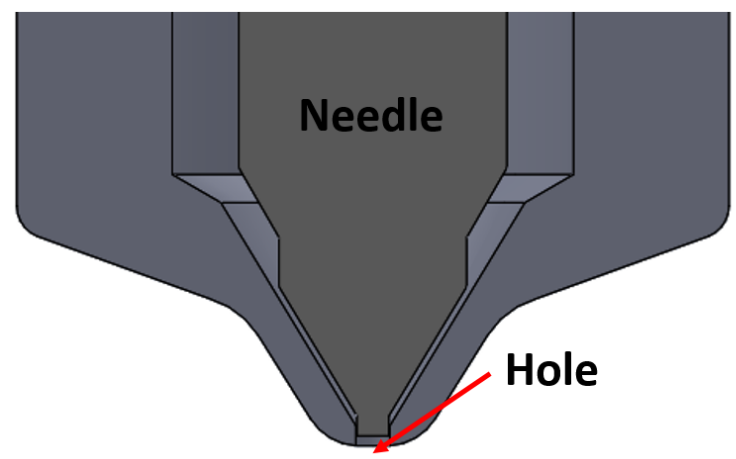

Figure 1: Comparison of standard and pintle nozzle concepts.

upstream section of the flow, which is controlled by the throttling effect achieved in the needle seat region. Thus, controlling the velocity at which the needle opens, it is possible to control as well the fuel injection rate [21].

In the case of a typical pintle nozzle (Figure 1.b) the needle lift affects not only the pressure upstream the hole, linked to the throttling effect in the needle seat, but also the area available for the flow. In the case shown in the previous figure (straight hole and needle shapes), in the initial stages of the injection, the flow has only the annular section available in the space between the hole and the needle, so the injection rate is small. When the needle tip overcomes the hole inlet, the area available for the flow suddenly increases, becoming equal to the outlet hole geometrical area, and the mass flow rate delivered would also increase. As a consequence, a so called boot-shape injection would be produced.

The concept proposed in this paper consists on using the pintle nozzle characteristics to control the temporal evolution of the area available for the flow. By a proper design of the relative shape between the needle and the nozzle hole, it is possible to produce injection rate shapes with different opening and closing characteristics, which can be 
Energy Conversion and Management 122 (2016) 419-427,

then adapted to the needs of a specific combustion system.

Another consideration that has to be made regarding the pintle nozzles used for the current study is that, during the initial stages of the injection, the structure of the spray itself would also be affected. This is due to the fact that, as previously described, at low needle lifts the flow passes through an annular section instead of the full nozzle hole. This can induce the formation of a hollow-cone spray when the needle lift is sufficiently low. As the needle goes up, the liquid fills the complete outlet section of the nozzle hole and a solid-cone spray is formed, as typical for diesel engine applications. According to previous studies in the literature [26], the hollow-cone spray show different primary atomization characteristics compared to the solid-cone. In this sense, Oda et al. 27] saw that arriving to a hollow-cone regime improved the spray atomization and mixing processes. This is consistent with findings from Martin et al. [28, who showed that the hollow-cone spray on a GDI injector promoted the formation of string structures, which was seen as an indicator for more efficient atomization.

\subsection{Geometries used}

Along the paper, three different pintle nozzle geometries are compared. A schematic of the geometrical characteristics of these nozzles is shown in Figure 2. In all cases, the outlet of the nozzle has a nominal outlet section of approximately $0.14 \mathrm{~mm}^{2}$ when the needle is fully open.

A

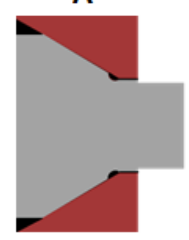

B

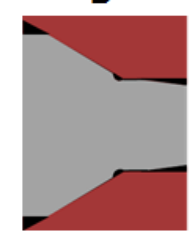

C

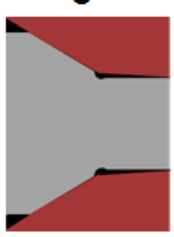

Figure 2: Schematic of pintle nozzle designs.

Nozzle A is characterized by straight shapes for both the needle and nozzle hole. In particular, the nozzle hole has a constant area, while the needle has two straight sections with different sizes, creating two levels of flow area as the needle lifts. Nozzle B maintains the straight hole, but has a straight-followed by a tapered-needle; while nozzle $\mathrm{C}$ has a straight needle and a tapered hole.

Another difference in the design of the nozzles is related to the nozzle hole length. In the case of nozzle A, the hole length is short and the needle protrudes in the discharge chamber when the injector is closed. This is done because, being the geometry fully cylindrical, there is no effect of the nozzle hole length on the relative gap between the needle and the nozzle (and, consequently, nor on the rate shaping characteristics). As a consequence, a short nozzle hole is preferred to increase the injection velocity and the spray angle. Contrarily, nozzles $\mathrm{B}$ and $\mathrm{C}$ have a larger nozzle hole length, so the needle arrives just to the end of the hole at the initial conditions. This way, it is possible to perform a smoother evolution of the gap between needle and nozzle hole.

Further explanation of the variable geometry nozzle assembly is shown in Fig. 3 for nozzle A. As previously explained, during the initial stages of the needle movement, only 
a small cross-sectional area is exposed for the fuel to be injected (initial) producing a low initial injection rate. The needle continues to move until the smaller needle diameter passes the nozzle throat, instantaneously exposing a larger flow area and thus higher injection rate (final). The combination of these rate profiles translates into a so-called boot injection rate shape which occurs at the start and end of the injection event, as will be seen in the results section.

In nozzle B, the initial part of the needle is straight. After a certain point, the needle transitions from straight to tapered shape, thus inducing a continuous increase of the available area as the needle moves up. As a consequence, it is expected that the injection rate is characterized by two regions: a low injection rate region, achieved by the straight shape, followed by another region with a relatively low slope compared to nozzle A. Additionally, the hole length has also been increased in order to enlarge this low-slope region In the case of nozzle C, the tapered geometry is produced directly in the hole, and a continuous increase of the injection rate is expected since the beginning of the injection event.

\section{Closed}

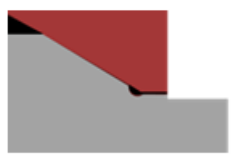

Initial

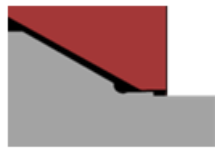

Final

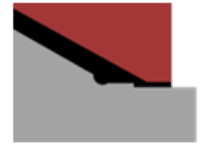

Figure 3: Detail of nozzle A design.

\section{Experimental tools and conditions}

In this section, the facilities and procedures used for the hydraulic and spray formation characterization of the different nozzle designs are described. Additionally, the boundary conditions used for each experimental campaign are detailed.

\subsection{Rate of Injection Meter}

The injection rate for each of the pintle nozzles was measured by an IAV Rate of Injection (ROI) Meter, based on Bosch's method. In this device, the injection was sprayed into a thin tube full of liquid fuel under controlled temperature and pressure. The injection produces a instantaneous pressure increase inside this tube, which was captured by a piezoelectric sensor placed close to the injector nozzle tip. This pressure increase was related to the instantaneous mass flow rate delivered by the injector. More information about the methodology can be found in [29]. 1

A summary of the experimental conditions tested along the study is shown in Table

\subsection{Momentum Flux test rig}

Spray momentum was characterized on a dedicated Momentum Flux test rig, consisting on a chamber pressurized up to $10 \mathrm{MPa}$. Nitrogen was used as the working fluid in order to ensure similar density values as the ones achieved inside the combustion 
Energy Conversion and Management 122 (2016) 419-427,

Table 1: Operating conditions for injection rate measurements.

\begin{tabular}{lc} 
Parameter & Values \\
\hline Injection Pressure [MPa] & $55,115,160,200$ \\
Backpressure [MPa] & $2.2,4.9,7.2$ \\
Energizing time [ms] & $0.4,0.8,1.1,2$
\end{tabular}

chamber of an internal combustion engine, but under non-reacting conditions. A measuring system, composed of a target and a piezoelectric pressure sensor, was placed in the spray axis at a $5 \mathrm{~mm}$ distance to capture the impact force of the spray. This force can be related to the momentum flux once the system has been properly setup [30. This information, combined with the Rate of Injection measurements, was post-processed to extract relevant information of the hydraulic performance of the nozzle, such as the effective injection velocity or the effective outlet diameter. The details of this post-processing, as well as the characteristics of the test rig itself, are available in 30. The conditions used for the momentum flux measurements are the same as for the injection rate, with the exception that only long energizing times $(2 \mathrm{~ms})$ were used.

\subsection{Optical diagnostics}

The facility used for the spray visualization tests, together with the two different optical diagnostic techniques and arrangements employed, are described below.

\subsubsection{High-pressure and high-temperature vessel}

All the spray visualization tests were conducted in a high-pressure and high-temperature vessel, seen in Figure 4. In this vessel, a heated constant pressure flow was provided with thermodynamic conditions up to $15 \mathrm{MPa}$ and $1000 \mathrm{~K}$, in order to reproduce typical engine in-cylinder values. This flow was controlled to values low enough not to produce significant interference with the spray dynamics, but high enough to ensure a proper cycle-to-cycle evacuation of the fuel and/or combustion products [21]. The injector was mounted on an injector holder, thermally insulated from the vessel, while the temperature of the injector was controlled with a coolant flow introduced in this injector holder. The vessel was equipped with three optical accesses: one opposite to the injector holder, and other two at 90 degrees from the injector axis.

\subsubsection{Liquid spray visualization}

Mie-scattering technique was used to characterize the liquid spray [31. In this technique, the spray was illuminated with two continuous high-intensity light sources. The main source was placed in the optical access opposite to the injector holder (i.e., in the same axis of the diesel spray), while the auxiliary source entered the vessel from one of the optical accesses parallel to the spray axis, with an angle of approximately 30 degrees. The light scattered from the liquid droplets is then captured by a Phantom high-speed CCD camera after passing through a beam splitter. This enabled the positioning of the camera and the auxiliary light source in the same side of the spray vessel. A schematic of this arrangement is shown in Figure 5

The high-speed camera was run at $41604 \mathrm{fps}$, allowing a temporal discretization of approximately $24 \mu s$ for the spray penetration. An image resolution of 720x160 pixels was achieved. 


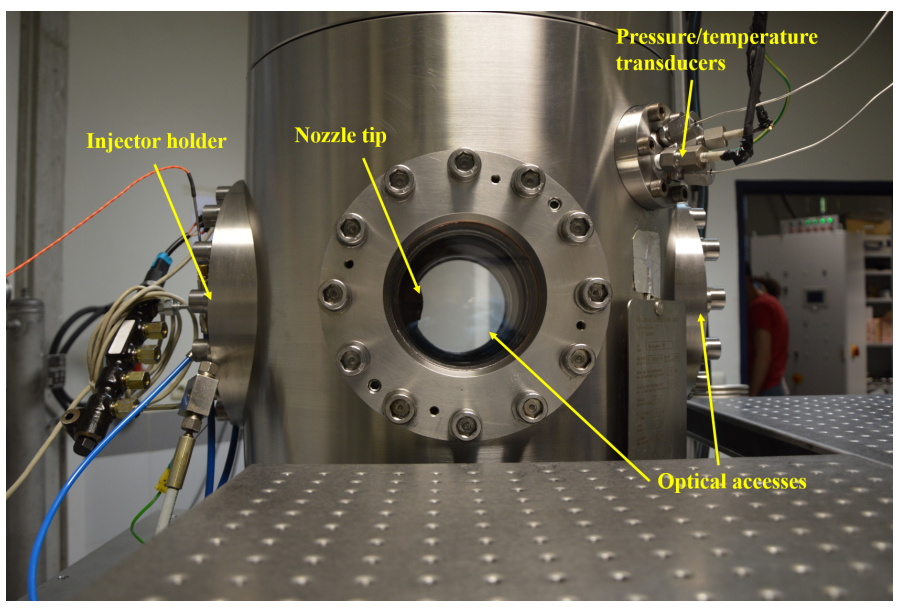

Figure 4: High-pressure and high-temperature vessel.

Table 2 shows a summary of the boundary conditions used for the liquid spray visualization tests. In all cases, the energizing time was fixed to $2 \mathrm{~ms}$, and a total of 8 repetitions were performed at each operating condition.

\begin{tabular}{lc} 
Table 2: Operating conditions for liquid spray visualization. \\
Parameter & Values \\
\hline Injection Pressure $[\mathrm{MPa}]$ & $55,115,160,200$ \\
Ambient density $\left[\mathrm{kg} / \mathrm{m}^{3}\right]$ & 17,25 \\
Ambient temperature $[\mathrm{K}]$ & 850,950
\end{tabular}

\subsubsection{Vapor spray visualization}

For the vapor spray visualization, a single-pass shadowgraphy technique was used 32. In this case, the light source entered the vessel from one side, after passing through a parabolic mirror, making the light beams parallel to each other. These light beams passed through the vessel and were refracted when passing through the spray due to its different refractive index. By positioning the CCD camera on the opposite side to the light source, it received only the light that has passed through the vessel without changing direction, and consequently created a negative image of the spray contour, including both liquid and vapor phases [31. An schematic is shown in Figure 6

A Photron high-speed CCD camera was used, set up at 60000 frames per second (16.6 $\mu s$ between consecutive images) and 576x200 pixels. The experimental conditions were the same already seen for the liquid spray visualization tests.

\section{Results}

In this section, the main results obtained along the study are summarized. First, the focus is pointed to the description of the hydraulic results, showing the injection rate 


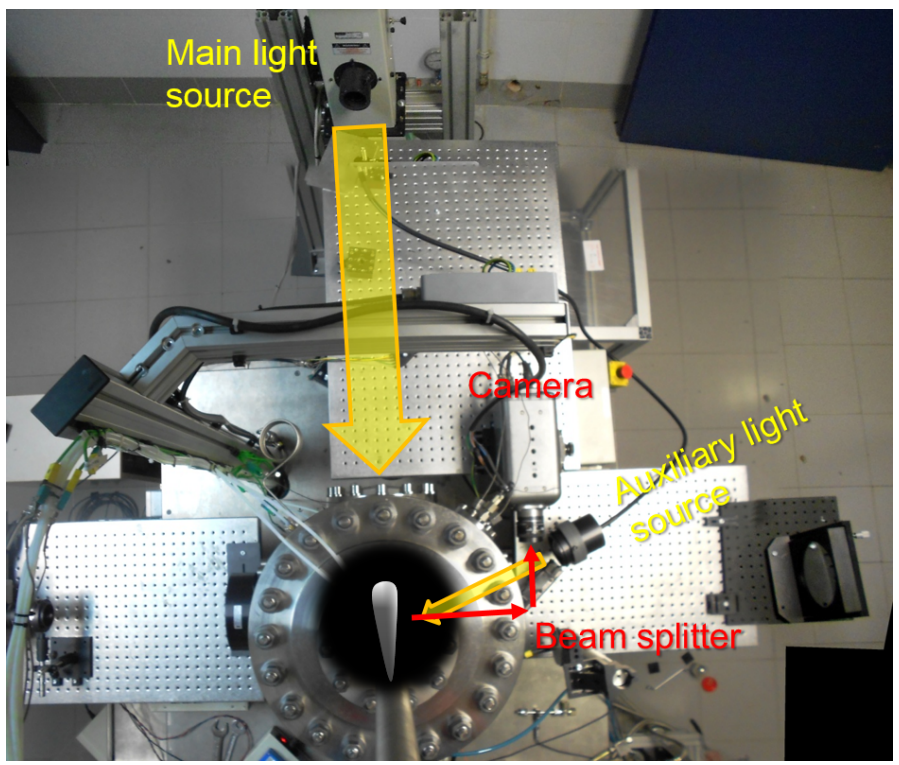

Figure 5: Optical arrangement for Mie-scattering liquid spray visualization.

shape characteristics of each design. Later on, the implications of each of these injection rate shaping characteristics on the spray penetration and angle are analyzed.

\subsection{Hydraulic behavior}

As stated in the first section, one of the most significant advantages of the pintle nozzles is the capability to adapt the shape of the injection rate. This is clearly shown in Figure 7, where a $2 \mathrm{~ms}$ pulse time at $55 \mathrm{MPa}$ injection pressure and $2.2 \mathrm{MPa}$ backpressure is depicted.

Focusing first on the curve representing nozzle A, the behavior previously anticipated is clearly observed. Up to approximately $0.4 \mathrm{~ms}$, the injection rate capability is limited to around $5 \mathrm{~g} / \mathrm{s}$ by the limited flow area available for the fluid at low needle lifts. As the needle continuous to move, the nozzle hole transitions to a larger flow area and the injection rate slope rapidly increases. The final flow rate approaches $35 \mathrm{~g} / \mathrm{s}$ flow characteristic of the real $\Delta p$ available and the discharge coefficient of the nozzle at these conditions.

In the case of nozzle $\mathrm{B}$, the injection rate is similar to nozzle $\mathrm{A}$ for the first portion since the nozzle hole remains constant. After reaching a certain lift, the separation between the needle and the seat began to increase due to the needle taper, resulting in an increasing but less aggressive injection rate profile relative to nozzle A. The injection rate continues to increase until the needle reaches its maximum lift at around $1.4 \mathrm{~ms}$.

Regarding nozzle $\mathrm{C}$, the straight needle combined with the tapered shape in the nozzle body produces a triangular shape from the beginning of the injection event. Nozzle C has a higher injection rate at the first injection stages compared to the other two pintle nozzles. However, the maximum injection rate is lower at maximum needle lift. 


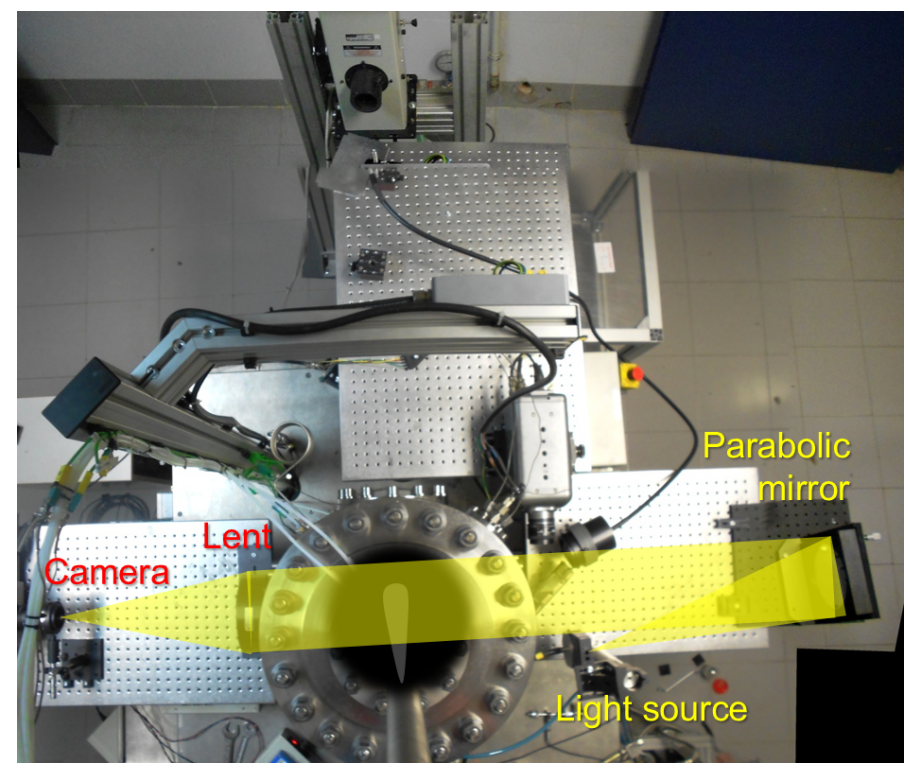

Figure 6: Optical arrangement for single-pass shadowgraphy.

In order to explain this lower value, the effective outlet section $A_{\text {eff }}$ is obtained from the combination of the injection rate and the momentum flux measurements at maximum needle lift [30. The results are offered as a function of the Reynolds number in Figure 8. This Reynolds number is defined as:

$$
R e=\frac{u_{t h} D_{o}}{\nu_{f}}
$$

where $D_{o}$ is the outlet hydraulic diameter of the nozzle hole and $u_{t h}$ is the theoretical velocity through the nozzle hole, calculated from Bernoulli's equation:

$$
u_{t h}=\sqrt{\frac{2 \Delta p}{\rho_{f}}}
$$

Nozzles A and B have similar values, with small differences due to the specific fluiddynamic features of each nozzle. It can be also noticed that, despite the nominal outlet area was set to $0.14 \mathrm{~mm}^{2}$, the actual value of the effective area is always higher than this value. This is due to a deviation induced during the prototyping process, which resulted in a real outlet area of approximately $0.16 \mathrm{~mm}^{2}$. In the case of nozzle $\mathrm{C}$, the effective outlet area has consistently lower values, also due to manufacturing differences, which lead to a real area of roughly $0.12 \mathrm{~mm}^{2}$. This kind of differences are linked to the prototype tooling and machining used, and should not be present in real production samples.

Injection rate results for 115 and $200 \mathrm{MPa}$ injection pressure are shown in Figures 9 and 10, respectively. The overall injection rate behavior is similar to the $55 \mathrm{MPa}$ test case. The increasing injection pressure results in faster needle dynamics, driving a faster transitioning through the nozzle hole area variation. 
Energy Conversion and Management 122 (2016) 419-427,

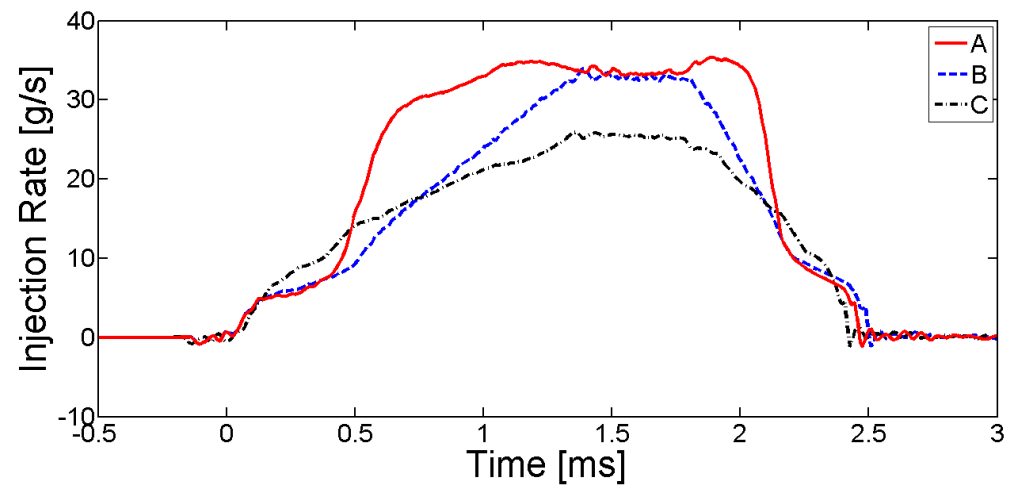

Figure 7: Comparison of injection rate shapes from the three pintle nozzles at $P_{i}=55 M P a$ and $P_{b}=2.2 M P a$.

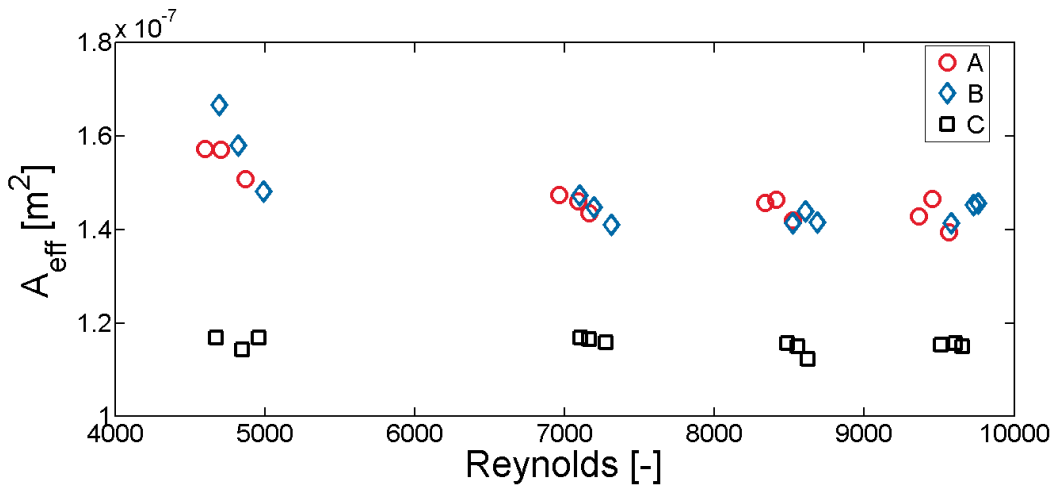

Figure 8: Evolution of the effective outlet section as a function of Reynolds number.

The injection rate shaping characteristics at the different injection pressures are in good agreement with the engine needs. At low-to-mid load, engine performance is severely limited by emissions and combustion noise, and more severe injection rate shaping may be beneficial. Near full-load conditions, these limitations become less significant and a square injection rate profile may be preferred to have a compact heat release rate profile.

The main advantage from this injection rate methodology is shown in Table 3 , where an analysis is made between two different injection rate shape methodologies for the 115 $\mathrm{MPa}$ condition. Considering nozzle A and the results already presented in figure 9, the mass flow rate at the initial lifts is estimated at around $20.8 \%$ of the mass flow rate at full needle lift conditions. From the combination of injection rate and momentum flux measurements, it can be stated that this lower flow is produced by the combination of an effective outlet velocity of approximately $68.2 \%$ and an effective outlet area of approximately $30.5 \%$ compared to the ones obtained at full needle lift conditions. If the same mass flow decrease is attempted with a variable pressure strategy, the change of effective outlet area would be negligible. Thus, the effective velocity would have to drop 
Energy Conversion and Management 122 (2016) 419-427,

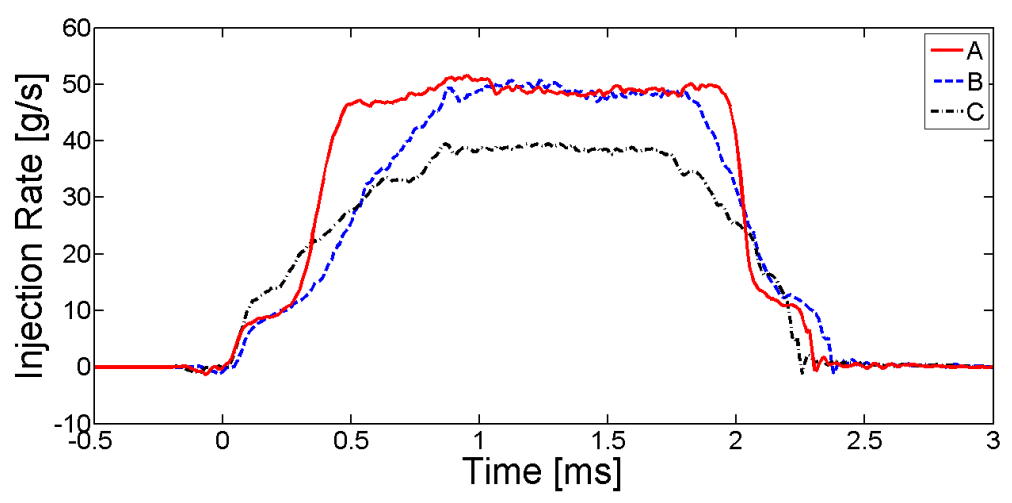

Figure 9: Comparison of injection rate shapes from the three pintle nozzles at $P_{i}=115 M P a$ and $P_{b}=2.2 M P a$.

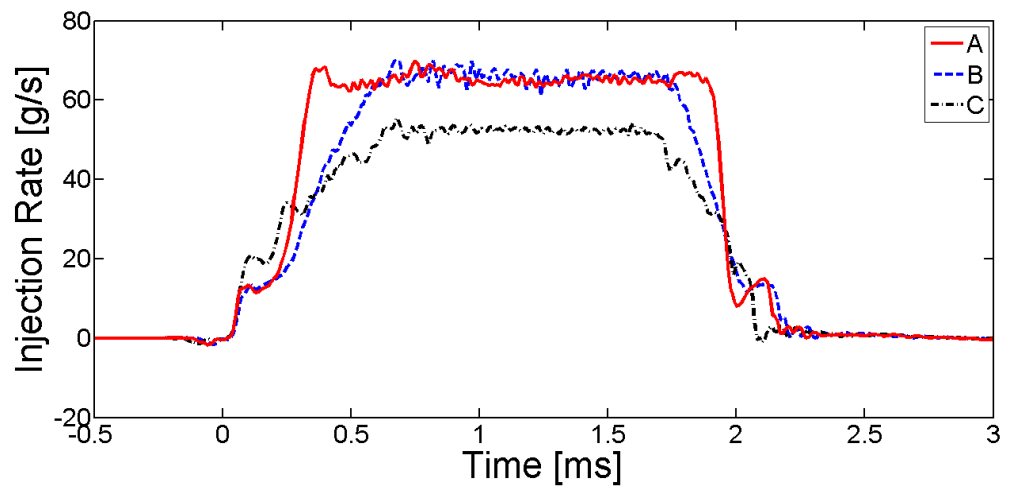

Figure 10: Comparison of injection rate shapes from the three pintle nozzles at $P_{i}=200 M P a$ and $P_{b}=2.2 M P a$.

to around $20.8 \%$ (more than three times lower than the pintle nozzle case), which would significantly impact atomization and spray penetration characteristics.

\subsection{Spray visualization}

Example images obtained from the shadowgraphy tests for a case with an injection pressure of $55 \mathrm{MPa}$ and vessel conditions of $25 \mathrm{~kg} / \mathrm{m}^{3}$ and $850 \mathrm{~K}$ are shown in Figure 11. Nozzle $\mathrm{C}$ shows higher penetration values at $0.45 \mathrm{~ms}$ after start of injection. This is consistent with the higher instantaneous mass flow delivered by this nozzle in the first phase of the injection rate as already discussed. As the injection event progresses to 1 ms, nozzle A exhibits a steeper increase in the instantaneous mass flow rate enabling its spray penetration to approach that of nozzle C. This can be seen at $1.7 \mathrm{~ms}$ after the start of injection, where nozzle A exhibits the longest spray. Regarding nozzle B, it shows the shortest penetration values up to $1.7 \mathrm{~ms}$ after the injection, which is consistent with the slower injection rate opening slope previously discussed.

When the injection event advances, it would be expected that nozzle $\mathrm{C}$ showed the shortest penetration due to its lower nozzle hole diameter. Nevertheless, since the opening 
Energy Conversion and Management 122 (2016) 419-427,

Table 3: Analysis of different injection rate shaping methodologies for $P_{i}=115 \mathrm{MPa}$ and $P_{b}=2.2 \mathrm{MPa}$.

\begin{tabular}{|l||l||lc||l|}
\hline Profile & $\begin{array}{l}\text { Mass flow ra- } \\
\text { tio }[\%]\end{array}$ & $\begin{array}{l}\text { Area ratio } \\
{[\%]}\end{array}$ & $\begin{array}{l}\text { Effective ve- } \\
\text { locity ratio } \\
{[\%]}\end{array}$ \\
\hline $\begin{array}{l}\text { Standard } \\
\text { Variable area (pin- } \\
\text { tle) }\end{array}$ & 100 & 100 & 100 \\
Variable pressure & 20.8 & 30.5 & 68.2 \\
\hline
\end{tabular}

slope of this nozzle was higher than in the other 2, the spray had already penetrated further. As a consequence, penetration of nozzle C stays consistently higher than the one of nozzle B up to arriving at $2.5 \mathrm{~ms}$ after the start of injection, where both nozzles show approximately the same penetration length. Nevertheless, it has to be noticed that in this case the vicinity to the vessel limits reduced the differences in penetration among the sprays.

Figure 12 shows the postprocessed values of spray penetration from the same operating condition as in figure 11. Vapor penetration for nozzle A has a significant change of slope at $0.6 \mathrm{~ms}$. This is linked to the change in injection rate slope previously discussed. Note that there is a $0.2 \mathrm{~ms}$ time lapse between the change in slope in the injection rate and the spray penetration linked to the time that the fuel parcels exiting the nozzle take to arrive the spray tip. Nozzles B and C exhibit a smoother behavior of the spray penetration as was expected from the injection rate measurements.

Different spray angle behavior is observed for the three nozzles. During the first stages of the injection, nozzles A and B show significantly higher values of spray angle compared to nozzle C. This is likely linked to the lower effective area achieved for these nozzles. As the lift approaches its maximum, the spray angle is primarily related to the hole geometry. Nozzles A and B (both with straight holes) approach similar values, while the tapered hole (nozzle C) remains consistently lower.

A similar kind of behavior is observed in Figure 13 for $200 \mathrm{MPa}$. In this case, the relative difference in the injection rate opening slope among the three pintle nozzle designs is much less pronounced which translated to similar spray characteristics. This behavior is consistent with the findings from the hydraulic measurement analysis. Again, nozzle $\mathrm{C}$ shows the fastest penetration during the initial phases of the injection, despite its lower geometrical diameter. Nozzle A achieves the longest penetration values after $0.5 \mathrm{~ms}$ beyond start of injection. The spray angles are practically identical for the three nozzles.

Mie scattering image examples are shown in Figure 14 for an injection pressure of $55 \mathrm{MPa}$ and vessel conditions of $25 \mathrm{~kg} / \mathrm{m}^{3}$ and $850 \mathrm{~K}$. At $0.45 \mathrm{~ms}$, the liquid phase penetration shows a similar behavior to the one already analyzed for the shadowgraphy vapor penetration data. This is due to the fact that in the initial phase of the injection the evaporation is low and the shadowgraphy images also represent the liquid spray. As the injection event continues, the liquid phase penetration stabilizes to a maximum value (called liquid length) that was similar for nozzles A and B, and approximately $10 \%$ lower for nozzle C.

Figure 15 shows the numerical result of the evolution of the liquid phase penetration for the same operating condition. Up to approximately $2 \mathrm{~ms}$, the behavior is the same as 


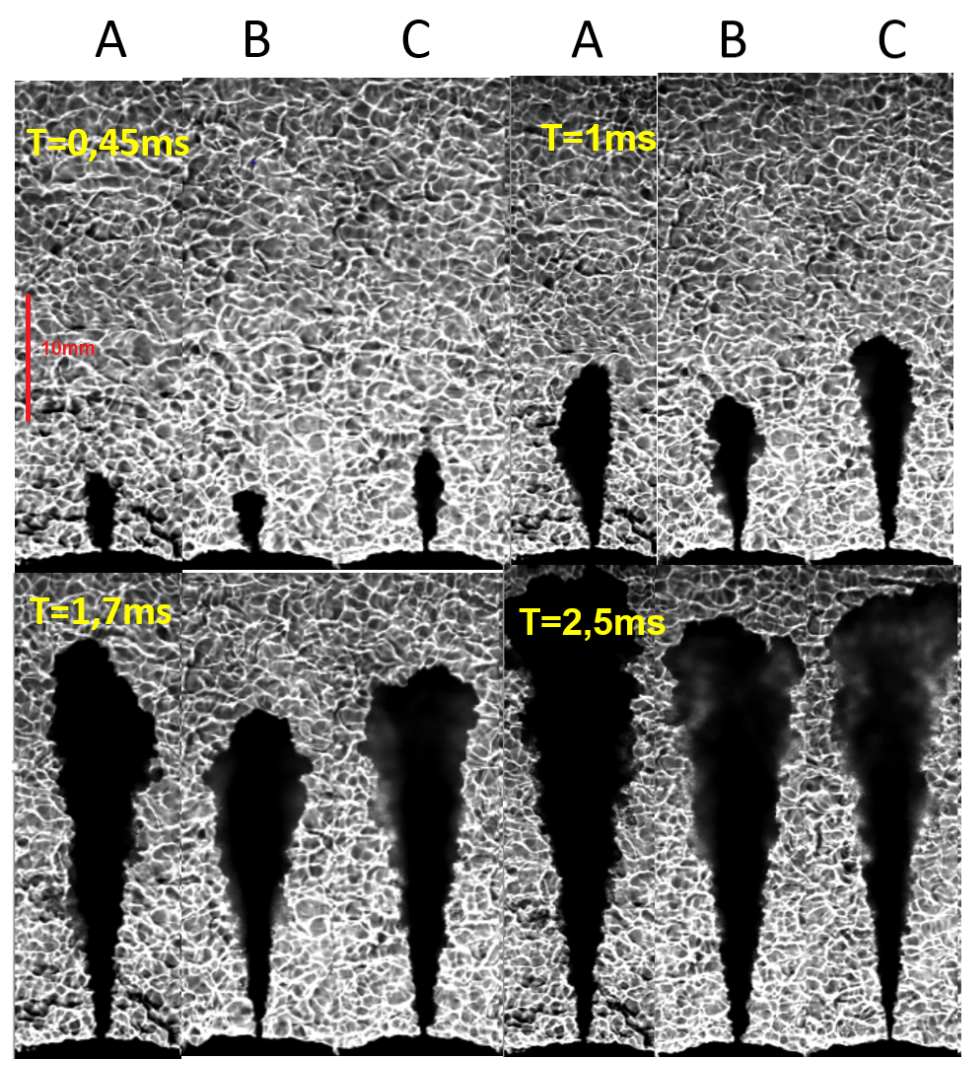

Figure 11: Sample shadowgraphy images (top left: $0.45 \mathrm{~ms}$ aSOI; top right: $1 \mathrm{~ms}$ aSOI; bottom left: $1.7 \mathrm{~ms}$ aSOI; bottom rigth: $2.5 \mathrm{~ms}$ aSOI). $P_{i}=55 \mathrm{MPa}, \rho_{a}=25 \mathrm{~kg} / \mathrm{m}^{3}, T_{a}=850 \mathrm{~K}$.

was already seen in figure 12 , Starting from there, liquid penetration stabilizes at values between $80 \mathrm{~mm}$ (nozzle C) and $95 \mathrm{~mm}$ (nozzle B).

Figure 16 shows in this case the liquid phase penetration for a $200 \mathrm{MPa}$ injection pressure and $950 \mathrm{~K}$ temperature. First, the $200 \mathrm{MPa}$ shows similar liquid penetration during the first stages of the injection event, and is consistent with the vapor phase penetration previously discussed. Additionally, the faster spray dynamics enables the spray to reach the stabilized liquid length in shorter time. Regarding the stabilized value shown in figure 16, nozzles $\mathrm{A}$ and $\mathrm{B}$ reach almost the same liquid length, while nozzle $\mathrm{C}$ clearly evaporates at a shorter distance.

The difference in stabilized liquid length among the nozzles can be explained in terms of the effective area behavior, as previously shown in figure 8 . The relationship between the liquid length and the effective area (or diameter) is highlighted in equation 3 33:

$$
L L \propto \frac{C_{a}^{1 / 2} D_{e f f}}{C_{m v}}
$$

where $C_{m v}$ is the fuel concentration needed to achieve the complete evaporation of 
Energy Conversion and Management 122 (2016) 419-427,

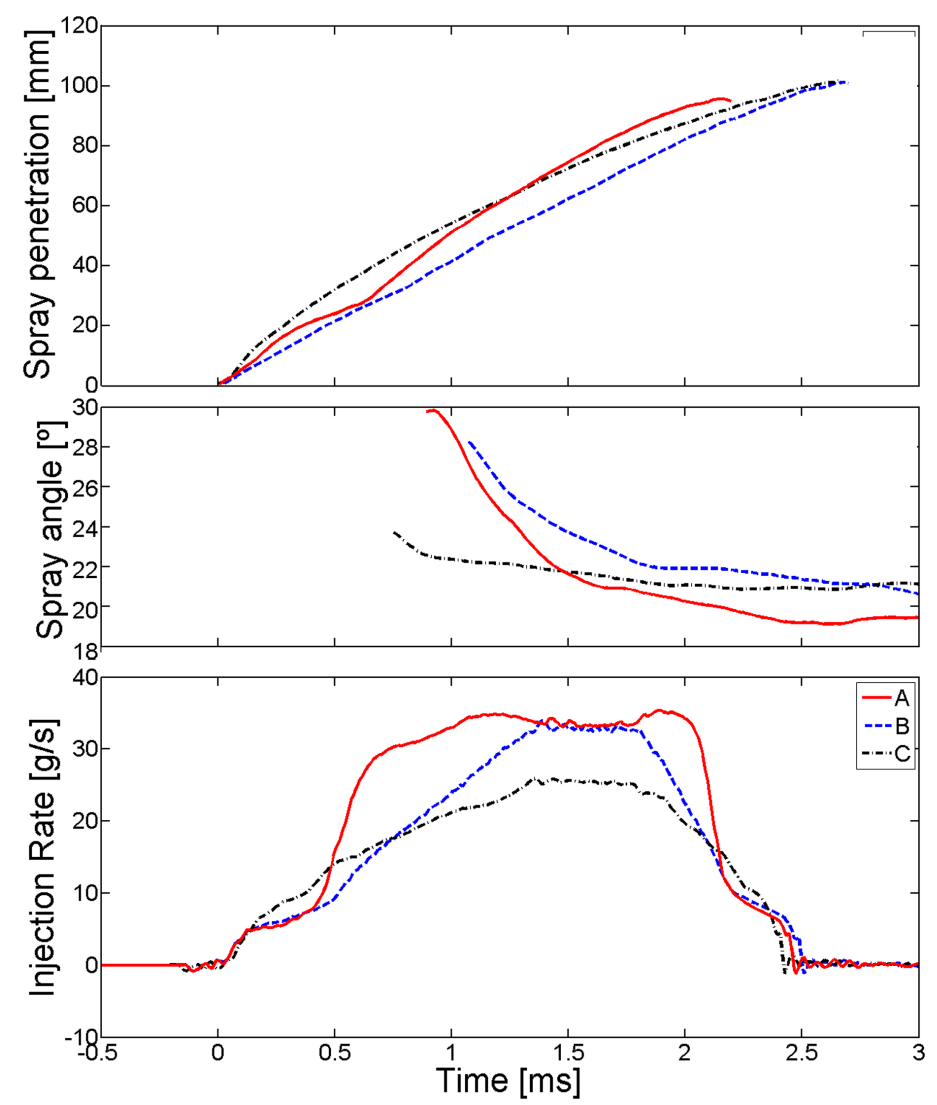

Figure 12: Comparison of spray penetration (top), spray angle (middle) and injection rate (bottom). $P_{i}=55 \mathrm{MPa}, \rho_{a}=25 \mathrm{~kg} / \mathrm{m}^{3}, T_{a}=850 \mathrm{~K}$.

the spray, which depends on the fuel characteristics and the operating temperature.

In order to better appreciate this behavior, Figure 17 depicts the stabilized liquid length for all the conditions tested against an effective equivalent diameter, which is defined as:

$$
D_{e f f, e q}=\sqrt{A_{e f f} \frac{\rho_{f}}{\rho_{a}}}
$$

As seen in the figure, all the measurements approximately collapse in two lines, which correspond to the two operating temperatures used along the visualization tests ( 850 and $950 \mathrm{~K})$.

Another point to be considered from these results is the relatively higher liquid length obtained compared to standard multi-hole nozzles for similar operating conditions. For example, Payri et al. [33] studied spray and combustion characteristics on 3 multihole diesel injection nozzles with relatively small diameter, finding liquid-length values between 16 and $21 \mathrm{~mm}$. In nozzles with larger diameter, Siebers 34 found values between 
Energy Conversion and Management 122 (2016) 419-427,

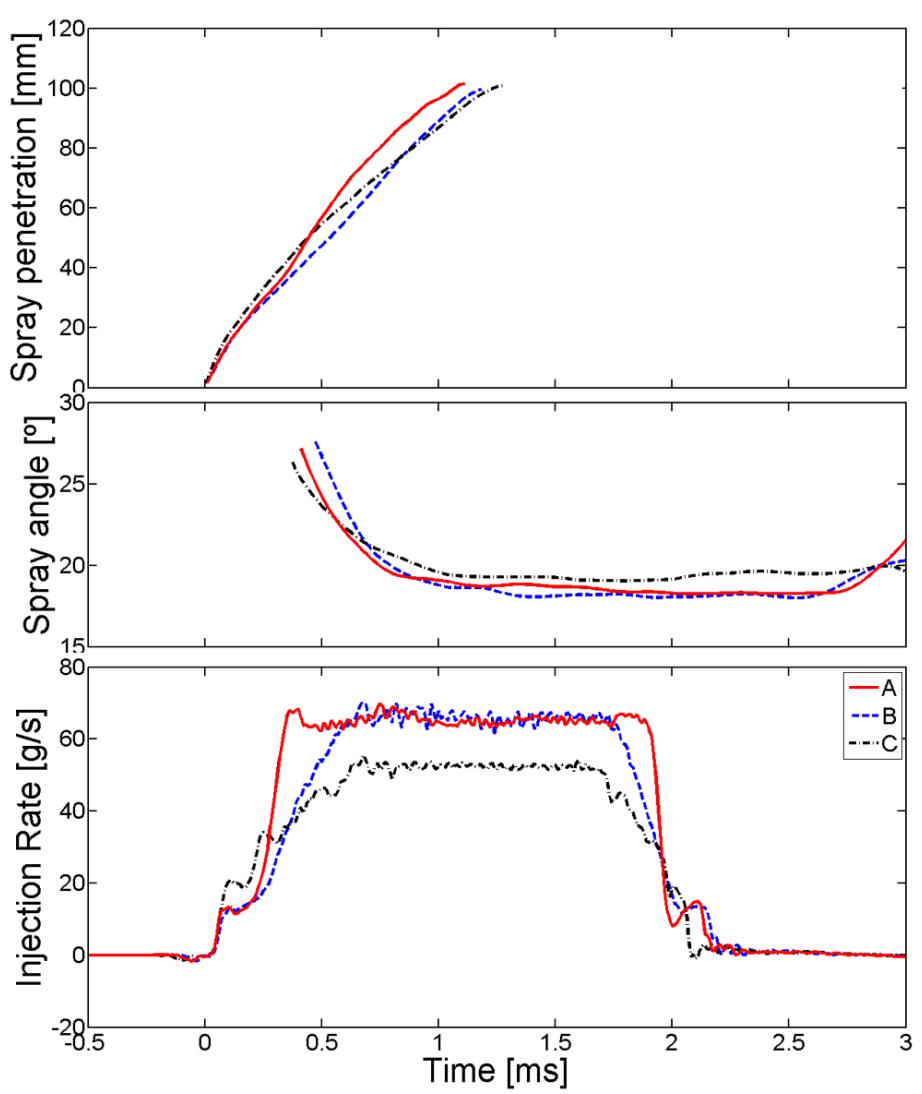

Figure 13: Comparison of spray penetration (top), spray angle (middle) and injection rate (bottom). $P_{i}=200 \mathrm{MPa}, \rho_{a}=25 \mathrm{~kg} / \mathrm{m}^{3}, T_{a}=850 \mathrm{~K}$.

20 and $45 \mathrm{~mm}$ for similar discharge densities. The longer liquid-length observed in the current study is linked to the geometrical area needle for the nozzle holes to deliver similar fuel quantities (being single-hole). This longer liquid-lengths could result in an impact of the liquid droplets onto the piston and/or liner walls, with expected drawbacks on emissions and oil dilution. Thus, the current nozzle concept cannot be directly applied to a state-of-the-art diesel combustion system, despite the potential achieved in rate shaping capabilities. One possibility would be to couple the pintle nozzle concept to a ultra-high pressure fuel injection system, so that it is possible to design the pintle nozzles with smaller diameters and without increasing significantly the injection and combustion durations. Another possible application of the concept would be on a sideinjection combustion system design. This would be the case of a 2-stroke opposed piston architecture, which may benefit from variable-area nozzle designs to balance performance, emissions and component thermal durability thanks to the extra flexibility of the pintlenozzle design. 


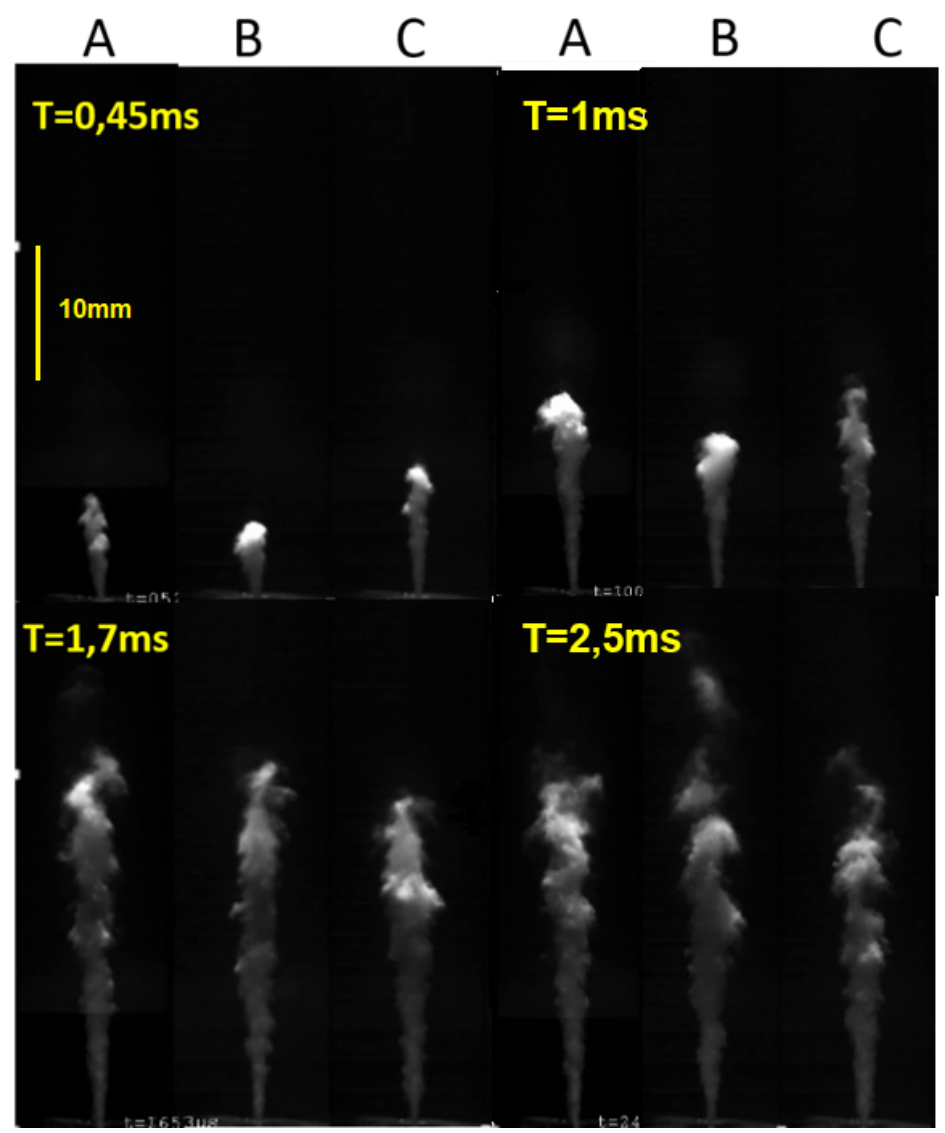

Figure 14: Sample Mie scattering images (top left: $0.45 \mathrm{~ms}$ aSOI; top right: $1 \mathrm{~ms}$ aSOI; bottom left: $1.7 \mathrm{~ms}$ aSOI; bottom rigth: $2.5 \mathrm{~ms}$ aSOI). $P_{i}=55 \mathrm{MPa}, \rho_{a}=25 \mathrm{~kg} / \mathrm{m}^{3}, T_{a}=850 \mathrm{~K}$.

\section{Conclusions}

In the current paper, a complete characterization of three pintle nozzle designs aimed at achieving different injection rate shaping characteristics was performed. The three pintle nozzle variants were a nozzle with straight hole and needle shapes, and two other geometries where a tapered section was implemented in either the needle or the hole.

The injection rate measurements show the capability of the three tested geometries to perform injection rate shaping compared to a traditional square-like injection profile. The straight pintle nozzle (nozzle A) is characterized by a boot-like injection rate, with a first phase of the injection approximately $20 \%$ of the nozzle's maximum flow capability. This lower flow phase also has a small influence on the injection pressure. Using this strategy, the flow velocity at the hole outlet during the initial injection phase is approximately $60 \%$ greater compared to a standard injector at the same pressure conditions. Attempting to achieve the same level of flow reduction with a variable pressure concept would imply significantly lower spray velocities resulting in unfavorable impacts on fuel atomization 
Energy Conversion and Management 122 (2016) 419-427,

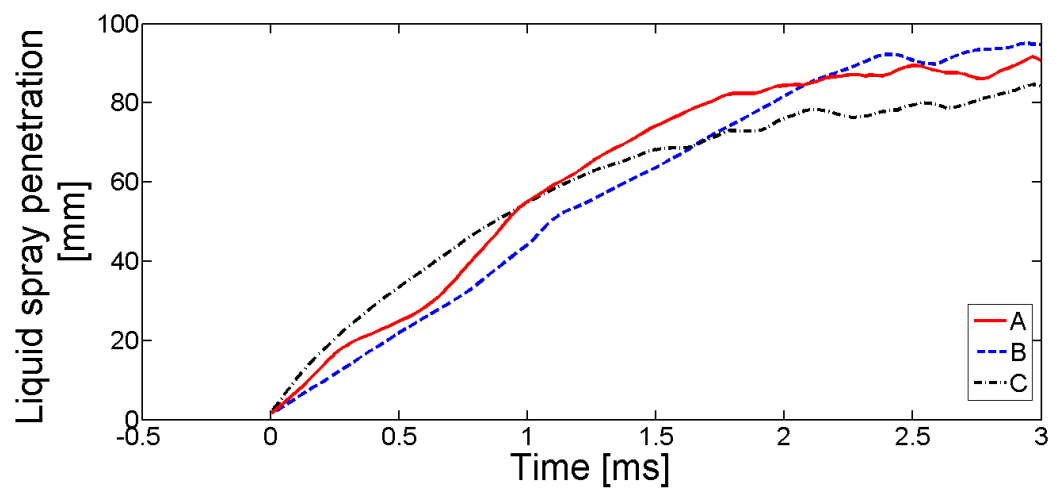

Figure 15: Evolution of liquid spray penetration. $P_{i}=55 M P a, \rho_{a}=25 \mathrm{~kg} / \mathrm{m}^{3}, T_{a}=850 \mathrm{~K}$.

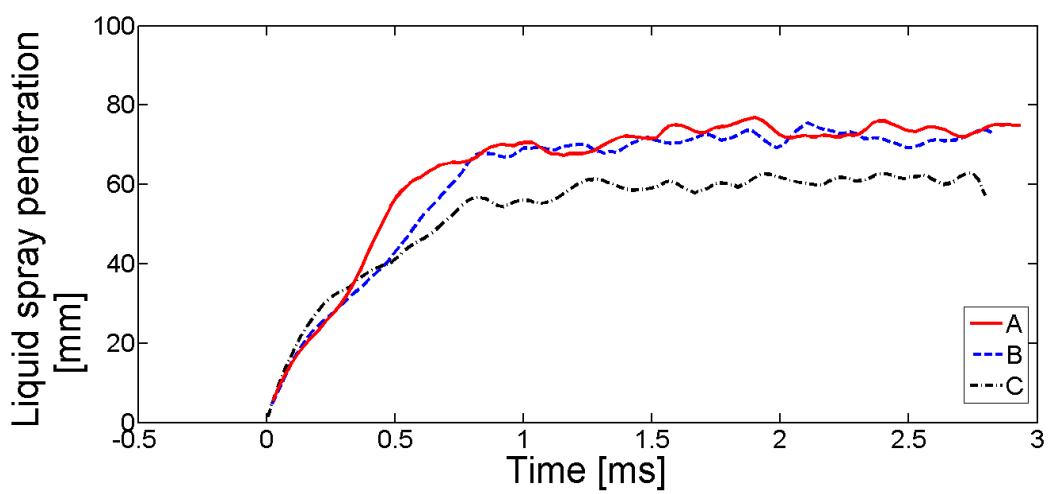

Figure 16: Evolution of liquid spray penetration. $P_{i}=200 M P a, \rho_{a}=25 \mathrm{~kg} / \mathrm{m}^{3}, T_{a}=950 \mathrm{~K}$.

and emissions characteristics.

The tapered needle (nozzle B), shows similar behavior to nozzle A during the first phase of the injection event, but then transitions in a smoother way up to the maximum flow capability. In the case of the tapered hole (nozzle C), a smooth injection profile is observed from the start of injection, resulting in a triangular injection rate shape.

Two different optical diagnostic techniques were used to evaluate the impact of the nozzle design on the spray behavior in a high-pressure and high-temperature vessel. Shadowgraphy results show the evolution of the full spray (liquid + vapor) in terms of spray penetration and spray angle. Spray penetration is in good agreement with the injection rate measurements, as was expected. In the case of the spray angle, the pintle designs have the most impact near the beginning of the injection event, while the final spray angle value depends more on the effective area of the hole.

Finally, Mie scattering was used to obtain information about the liquid length. This parameter is primarily dependent on the thermodynamic conditions of the vessel, as was demonstrated from previous studies available in the literature. Through the combination of injection rate and momentum flux measurements, the influence of the pintle nozzle designs on injector behavior is shown to primarily depend on the differences in the nozzle 


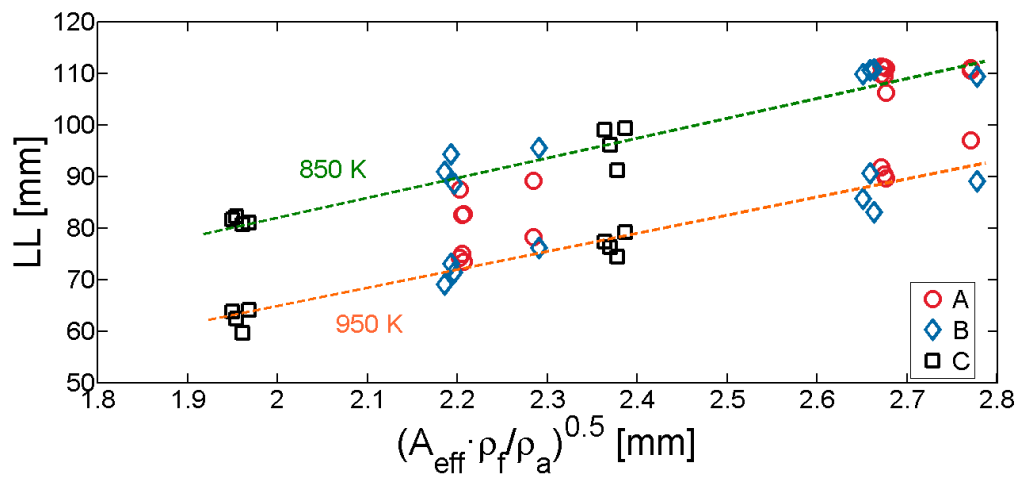

Figure 17: Summary of stabilized liquid length for all conditions tested.

effective area. In any case, the high effective area results in liquid length values two or three times higher than those characteristic of typical diesel multi-hole injectors. Thus, tailoring the pintle nozzle hole geometry to a specific combustion system design would be required to manage spray quality and penetration to meet engine performance and emission targets.

\section{References}

[1] Z.-Y. Sun, G.-X. Li, C. Chen, Y.-S. Yu, G.-X. Gao, Numerical investigation on effects of nozzles geometric parameters on the flow and the cavitation characteristics within injectors nozzle for a high-pressure common-rail DI diesel engine, Energy Conversion and Management 89 (2015) 843861. doi:10.1016/j.enconman.2014.10.047

[2] G. Jiang, Y. Zhang, H. Wen, G. Xiao, Study of the generated density of cavitation inside diesel nozzle using different fuels and nozzles, Energy Conversion and Management 103 (2015) 208-217. doi:10.1016/j.enconman.2015.06.065

[3] F. J. Salvador, J. Martínez-López, M. Caballer, C. De Alfonso, Study of the influence of the needle lift on the internal flow and cavitation phenomenon in diesel injector nozzles by CFD using RANS methods, Energy Conversion and Management 66 (2013) 246-256. doi:10.1016/j . enconman.2012. 10.011

[4] J. P. Viera, R. Payri, A. B. Swantek, D. J. Duke, N. Sovis, A. L. Kastengren, C. F. Powell, Linking instantaneous rate of injection to X-ray needle lift measurements for a direct-acting piezoelectric injector, Energy Conversion and Management 112 (2016) 350-358 doi:10.1016/j .enconman.2016. 01.038

[5] C. Dumouchel, On the experimental investigation on primary atomization of liquid streams, Experiments in Fluids 45 (3) (2008) 371-422. doi:10.1007/s00348-008-0526-0

[6] R. Payri, F. J. Salvador, J. Gimeno, J. De la Morena, Analysis of Diesel spray atomization by means of a near-nozzle field visualization technique, Atomization and Sprays 21 (9) (2011) 753-774. doi:10.1615/AtomizSpr.2012004051

[7] F. J. Salvador, S. Ruiz, J. Gimeno, J. De la Morena, Estimation of a suitable Schmidt number range in diesel sprays at high injection pressure International Journal of Thermal Sciences 50 (9) (2011) 1790-1798. doi:10.1016/j.ijthermalsci.2011.03.030 URL http://linkinghub.elsevier.com/retrieve/pii/S1290072911001165

[8] L. M. Pickett, D. L. Siebers, Soot in diesel fuel jets: Effects of ambient temperature, ambient density, and injection pressure, Combustion and Flame 138 (1-2) (2004) 114-135. doi:10.1016/j. combustflame.2004.04.006.

[9] L. M. Pickett, J. Manin, R. Payri, M. Bardi, J. Gimeno, Transient Rate of Injection Effects on Spray Development, SAE Technical Paper 2013-24-001 (2013) 15-16 doi:10.4271/2013-24-0001 
Energy Conversion and Management 122 (2016) 419-427,

[10] J. Johnson, J. Naber, S.-Y. Lee, G. Hunter, R. Truemner, T. Harcombe, Correlations of NonVaporizing Spray Penetration for 3000 Bar Diesel Spray Injection, SAE Technical Paper 2013-240033 doi:10.4271/2013-24-0033

[11] J. a. Wloka, S. Pflaum, G. Wachtmeister, Potential and Challenges of a 3000 Bar Common- Rail Injection System Considering Engine Behavior and Emission Level, SAE Int. J. Engines 3 (1) (2010) 801-813. doi:10.4271/2010-01-1131

[12] B. Mohan, W. Yang, S. K. Chou, Fuel injection strategies for performance improvement and emissions reduction in compression ignition engines: A review, Renewable and Sustainable Energy Reviews 28 (2013) 664-676. doi:10.1016/j.rser.2013.08.051.

[13] B. Mahr, Future and Potential of Diesel Injection Systems, Proceedings of THIESEL 2002 Conference on Thermo- and Fluid-Dynamic Processes in Diesel Engines (2002) 5-17.

[14] T. Fang, R. E. Coverdill, C.-f. F. Lee, R. A. White, Effects of injection angles on combustion processes using multiple injection strategies in an HSDI diesel engine, Fuel 87 (2008) 3232-3239. doi:10.1016/j.proci.2008.07.031

[15] A. Dhar, A. K. Agarwal, Experimental investigations of the effect of pilot injection on performance, emissions and combustion characteristics of Karanja biodiesel fuelled CRDI engine, Energy Conversion and Management 93 (2015) 357-366. doi:10.1016/j.enconman.2014.12.090

[16] M. Xu, W. Chein, H. Zhang, T. An, S. Zhang, Effect of diesel pre-injection timing on combustion and emission characteristics of compression ignited natural gas engine, Energy Conversion and Management 117 (2016) 86-94. doi:10.1016/j.enconman.2016.02.054

[17] H. Juneja, Y. Ra, R. D. Reitz, Optimization of Injection Rate Shape Using Active Control of Fuel Injection (2004). doi:10.4271/2004-01-0530

[18] B. Mohan, W. Yang, W. Yu, K. L. Tay, S. K. Chou, Numerical investigation on the effects of injection rate shaping on combustion and emission characteristics of biodiesel fueled CI engine, Applied Energy 160 (2015) 737-745 doi:10.1016/j.apenergy.2015.08.034

[19] Z. He, T. Xuan, Y. Xue, Q. Wang, L. Zhang, A numerical study of the effects of injection rate shape on combustion and emission of diesel engines, Thermal Science 18 (1) (2014) 67-78. doi: 10.2298/TSCI130810013H

[20] J. Benajes, S. Molina, K. De Rudder, T. Rente, Influence of Injection Rate Shaping on Combustion and Emissions for a Medium Duty Diesel Engine, Journal of Mechanical Science and Technology 20 (9) (2006) 1436-1448.

[21] V. Macian, R. Payri, S. Ruiz, M. Bardi, A. H. Plazas, Experimental study of the relationship between injection rate shape and Diesel ignition using a novel piezo-actuated direct-acting injector, Applied Energy 118 (2014) 100-113. doi:10.1016/j .apenergy.2013.12.025

[22] L. Postrioti, S. Malaguti, M. Bosi, G. Buitoni, S. Piccinini, G. Bagli, Experimental and numerical characterization of a direct solenoid actuation injector for Diesel engine applications, Fuel 118 (2014) 316-328. doi:10.1016/j.fuel.2013.11.001

[23] S. d'Ambrosio, A. Ferrari, Effects of pilot injection parameters on low temperature combustion diesel engines equipped with solenoid injectors featuring conventional and rate-shaped main injection, Energy Conversion and Management 110 (2016) 457-468. doi:10.1016/j.enconman.2015.12.114

[24] R. Venugopal, N. Abani, R. Mackenzie, Effects of Injection Pattern Design on Piston Thermal Management in an Opposed-Piston Two-Stroke Engine, SAE Technical Paper 2013-01-2423 doi: 10.4271/2013-01-2423

[25] M. Son, K. Yu, J. Koo, O. C. Kwon, J. S. Kim, Effects of momentum ratio and Weber number on spray half angles of liquid controlled pintle injector, Journal of Thermal Science 24 (1) (2015) 37-43. doi:10.1007/s11630-015-0753-7

[26] M. Linne, Imaging in the optically dense regions of a spray: A review of developing techniques, Progress in Energy and Combustion Science 39 (2013) 403-440. doi:10.1016/j.pecs.2013.06.001

[27] T. Oda, Y. Goda, S. Kanaike, K. Aoki, K. Ohsawa, K, Experimental Study about internal Cavitating Flow and Primary Atomization of a Large-Scaled VCO Diesel Injector with Eccentric Needle, Proceedings of 11th Triennial International Annual Conference on Liquid Atomization and Spray Systems (2009).

[28] D. Martin, M. Cardenas, P. Pischke, R. Kneer, Experimental investigation of near nozzle spray structure and velocity for a GDI hollow cone spray, Atomization and Sprays 20 (12) (2010) 10651076. doi:10.1615/AtomizSpr.v20.i12.40

[29] R. Payri, F. J. Salvador, J. Gimeno, G. Bracho, A new methodology for correcting the signal cumulative phenomenom on injection rate measurements, Experimental Techniques 32 (February) (2008) 46-49. doi:10.1111/j.1747-1567.2007.00188.x

[30] R. Payri, J. M. Garcia-Oliver, F. J. Salvador, J. Gimeno, Using spray momentum flux measurements 
Energy Conversion and Management 122 (2016) 419-427,

to understand the influence of diesel nozzle geometry on spray characteristics, Fuel 84 (5) (2005) 551-561. doi:10.1016/j.fuel.2004.10.009

[31] R. Payri, F. J. Salvador, A. Garcia, A. Gil, Combination of visualization techniques for the analysis of evaporating diesel sprays, Energy and Fuels 26 (2012) 5481-5490. doi:10.1021/ef3008823.

[32] Y. J. Ma, R. H. Huang, P. Deng, S. Huang, The development and application of an automatic boundary segmentation methodology to evaluate the vaporizing characteristics of diesel spray under engine-like conditions, Measurement Science and Technology 26 (4) (2015) 045004. doi:10.1088/ 0957-0233/26/4/045004

[33] R. Payri, F. J. Salvador, J. Gimeno, J. De la Morena, Effects of nozzle geometry on direct injection diesel engine combustion process, Applied Thermal Engineering 29 (10) (2009) 2051-2060. doi: $10.1016 / j$.applthermaleng.2008.10.009

[34] D.L. Siebers, Scaling liquid-phase fuel penetration in diesel sprays based on mixing-limited vaporization, SAE Technical Paper 1999-01-0528doi:10.4271/1999-01-0528 